\title{
Uber and the Sharing Economy, Changing Strategies and Global Markets: An Abstract
}

\author{
Syed Tariq Anwar
}

\begin{abstract}
The purpose of this case-based research is to investigate Uber and its global markets and changing strategies in the sharing economy and transportation networks and logistics services industry. Uber is a part of the sharing economy as well as transportation network and logistics services industry and carries a unique business model. Uber and its competitors often seek business models which are synonymous with collaborative consumption. First introduced in 2009, Uber has become an ambitious and aggressive firm regarding its global operations and operates in over 400 cities in 60 countries.

As expected, Uber has gone through major changes to become a global brand in the taxi-hailing industry. The company pursued a simple strategy based on its apps and consumer convenience. Behind Uber's early successes, we find organizational blunders, managerial mistakes, and growth hurdles. Uber can pursue growth and expansion if quality and service is maintained by the company. Also technology plays an important role in the digital economy. As of 2017, the company clearly enjoys its distinct brand image and good visibility in the USA and international markets. Within the areas of international marketing, evolutionary growth, and global strategies, the case analyzes and discusses the Uber brand and its current and future potential. At the same time, regulators in global markets will continue to investigate the company because of its business model, corporate networks, and questionable labor practices.
\end{abstract}

References Available Upon Request

S.T. Anwar $(\bowtie)$

West Texas A\&M University, Canyon, TX, USA

e-mail: sanwar@mail.wtamu.edu 